процессов в семейных отношениях, актуальна идея создания специализированных судов по семейным делам. Также необходимо усилить государственную и общественную поддержку семьи в целом.

1. Семейное право. - М.: АСТ, Сова, ВКТ, 2016. - 160 с.

2. Семейный кодекс Российской Федерации: принят 29 декабря 1995 № 223-Ф3 (ред. от 02.07.2021) // Собрание законодательства Российской Федерации. - 1996. - 1 января. - № 1. - Ст. 16.

3. Гражданский процессуальный кодекс Российской Федерации от 14.11.2002 № 138-Ф3 (ред. от 01.07.2021) // Собрание законодательства РФ. - 18.11.2002. - № 46. - ст. 4532.

4. Антокольская М. В. Семейное право: Учебник. М.: Норма, 2013. - 432c.

5. Лозовская С.О. Семейное право: Учебник для бакалавров. М., Проспект, 2014. -368c.

6. Кудрявцева Л.В. О проблемных вопросах правового регулирования, связанных с лишением и ограничением родителей родительских правах / в сборнике: Научное обеспечение Агропромышленного комплекса. сборник статей по материалам 72-й научно-практической конференции преподавателей по итогам НИР за 2016 г. 2017. - С. 652-653.

7. Федеральный закон от 17.01.1992 № 2202-1 (последняя редакция)) «О прокуратуре Российской Федерации» // Собрание законодательства РФ. - 20.11.1995. - № 47. - ст. 4472.

8. Федеральный закон от 24 июня 1999 г. № 120-Ф3 «Об основах системы профилактики безнадзорности и правонарушений несовершеннолетних» (последняя редакция)// СЗ РФ. - 1999. - № 26. - С. 3177.

9. Рясенцев, В. А. Семейное право / В.А. Рясенцев. - М.: Юридическая литература, 2016. - 296 с.

10. Подольская А.С., Кудрявцева Л.В. Осуществление и защита родительских прав / В сборнике: Научное обеспечение агропромышленного комплекса. Сборник статей по материалам 74-й научно-практической конференции студентов по итогам НИР за 2018 год. Ответственный за выпуск А.Г. Кощаев. 2019. С. 13641366.

11. Kudryavtseva L., Kudyalova N. Conflict issues of family law in the modern international private law // Актуальные проблемы современности. 2017. № 4 (18). С. 48-53.

\title{
Нуралиева Д.Х. \\ Производство дознания в отношении несовершеннолетних в условиях реализации законопроекта о введении в российское уголовное законодательство института уголовного проступка
}

Московский государственный университет технологий и управления имени К.Г. Разумовского (Первый казачий университет) (Россия, Москва)

doi: 10.18411/trnio-12-2021-188

Научный руководитель: Котяжов А.В.

\section{Аннотация}

В настоящей статье рассмотрены некоторые проблемы правоприменительной практики, связанные с принятием законопроекта о ведении в уголовное законодательство России института уголовного проступка и его реализацией при производстве дознания в отношении несовершеннолетних.

Ключевые слова: несовершеннолетний, подозреваемый, уголовный проступок, обеспечение прав и свобод.

\section{Abstract}

This article discusses some of the visible problems of law enforcement practice related to the investigation of minors in the adoption of the draft law on the introduction of the institution of criminal misconduct in the criminal legislation of Russia.

Keywords: minor, suspect, criminal offense, ensuring rights and freedoms.

Несовершеннолетние граждане в системе уголовно-правовых отношений являются субъектами особой уголовно-правовой охраны, а в случае привлечения к уголовной ответственности таких лиц предусмотрены особый порядок расследования уголовных дел, 
применение мер воспитательного воздействия либо значительное смягчение мер уголовнопроцессуального принуждения и наказания.

Согласно статистическим данным ФКУ ГИАЦ МВД России о состоянии преступности в Российской Федерации за 2020 год количество преступлений, совершенных несовершеннолетними и при их участии уменьшилось по сравнению с аналогичным периодом прошлого года на 9,1 \% и составило 37771 преступление. Это свидетельствует, прежде всего, о высокой эффективности организации профилактической работы подразделений МВД России в отношении таких лиц и преступлений.

Так сотрудниками органов внутренних дел в анализируемом периоде было выявлено 852506 лиц (100\%), совершивших преступления, при этом удельный вес несовершеннолетних лиц в общем числе выявленных лиц составил 3,9 \%, что на 11,5\% меньше по сравнению с 2019 г., а именно 33575 несовершеннолетних, в числе которых 23976 несовершеннолетних являются учащимися и студентами, что составляет 71,4 \% от общего числа несовершеннолетних [1].

Данный показатель указывает на необходимость реализации дополнительных мер по выявлению причин и условий совершения преступлений указанной категорией несовершеннолетних граждан.

Так, например, только сотрудниками московской полиции за 2019 год выявлено и поставлено на профилактический учет более 3,5 тыс. неблагополучных семей и свыше 5700 несовершеннолетних правонарушителей, при этом на 27 \% сократилась преступность среди несовершеннолетних, а количество подростков, совершивших преступления, уменьшилось на $17 \%$ [2].

Несовершеннолетние, ставшие субъектами уголовно-процессуальных правоотношений, в связи с совершенными ими преступлениями небольшой и средней тяжести, преимущественно вовлекаются в сферу уголовно-процессуальной деятельности, реализуемой дознавателями органов внутренних дел.

В феврале текущего года Верховным Судом Российской Федерации (Далее - ВС РФ) был внесен законопроект [3], предусматривающий введение института уголовного проступка, который по мнению ВС РФ приведет к гуманизации уголовного закона.

Однако, в официальном отзыве Правительства Российской Федерации на законопроект, отмечается, что вводимое понятие уголовного проступка сводится к перечислению статей, по которым, при условии совершения лицом преступного деяния небольшой и средней тяжести и примирения с потерпевшим возможно прекращение уголовного преследования. Декриминализация таких преступлений и отнесение их к числу административных правонарушений может привести к затруднению процедуры их выявления и документирования [4].

Мы считаем, что необходимо согласиться с указанными существенными замечаниями относительно вводимого правового института. Действительно на практике может возникнуть неопределенность в применении уже действующих норм уголовного и уголовнопроцессуального законодательства. Например, конкуренция норм о выборе основания для прекращения уголовного преследования или уголовного дела при применении новой редакции ст. 25.1 УПК РФ. Вместе с тем, в предложенном законопроекте не предусмотрено четкое определение срока направления в суд ходатайства о прекращении уголовного дела или уголовного преследования в отношении лица, подозреваемого (обвиняемого) в совершении уголовного проступка. Следует также отметить, что в рассматриваемом законопроекте отсутствует конкретное разъяснение особенностей правовой природы, отличающей уголовный проступок от преступления.

Исходя из сложившейся правоприменительной практики, к лицу, привлекаемому к уголовной ответственности по делам небольшой и средней тяжести, особенно когда к уголовной ответственности привлекаются несовершеннолетние, судами крайне редко применяется наказание в виде лишения свободы, поэтому представляется не совсем ясным как отразятся последствия такой «гуманизации» на существующем уровне защиты прав 
несовершеннолетних в т.ч. ставших жертвами преступлений и качестве жизни российского общества в целом.

Следует также отметить, что в тексте законопроекта нет никаких разъяснений по производству предварительного расследования в форме дознания в отношении несовершеннолетних, по уголовным делам о преступлениях, отнесенных законопроектом к числу «уголовного проступка». Так положениями ст. 226.2 УПК РФ производство дознания в сокращенной форме в отношении подозреваемых, являющихся несовершеннолетними, безоговорочно исключается. Отсюда следует, что дознание по данной категории уголовных дел будет осуществляться с применением норм УПК РФ в общем порядке с соблюдением всех процессуальных процедур и сроков, направлением уголовного дела с постановлением о прекращении уголовного преследования и возбуждении перед судом ходатайства о применении к несовершеннолетнему обвиняемому принудительной меры воспитательного воздействия. После чего, исходя из текста проекта федерального закона, последует передача уголовного дела в суд, который обязан прекратить уголовное дело в отношении несовершеннолетнего обвиняемого, освободив его от уголовной ответственности и применив к нему иные меры уголовно-правового характера, не являющиеся уголовным наказанием.

Так, согласно закону, к несовершеннолетнему будут применены принудительные меры воспитательного воздействия, к которым относятся предупреждение, передача под надзор родителей либо специализированного государственного органа, возложение обязанности загладить причиненный вред, ограничение досуга и установление особых требований к поведению несовершеннолетнего. Срок применения таких мер, как передача под надзор или ограничение досуга, может составлять от одного месяца до года.

При этом сохраняется действие нормативное положение о том, что несовершеннолетний, совершивший преступления небольшой или средней тяжести впервые, не отнесенные к уголовному проступку, может быть освобожден от ответственности, если на него можно повлиять посредством применения принудительных мер. В случае систематического неисполнения несовершеннолетним принудительной меры воспитательного воздействия эта мера по представлению специализированного государственного органа отменяется, материалы направляются для привлечения несовершеннолетнего к уголовной ответственности [5].

Вместе с тем, представляется важным на уровне законодателя разъяснить порядок подачи сведений в информационно-аналитический центр на этапах возбуждения уголовного дела и после принятия судом решения о прекращении уголовного дела с применением принудительных мер воспитательного воздействия в отношении несовершеннолетних, ввиду того, что такие данные в последствие отображаются в справках о судимости. Это может в дальнейшем отразиться на принятии решений о наложении ограничении на занятие данным лицом определенных должностей.

Так, Председатель ВС РФ В.М. Лебедев придерживается мнения, что «Самое главное, что люди, попавшие под статью за проступок, не получат судимости. Это спасает человека от дальнейших неприятностей в жизни. Ведь судимым людям закрыты многие пути. Так что если человек возьмется за ум, его проступки станут фактом истории, но никак не пятном в биографии» [6].

Однако стоит отметить, что именно такой негативный исход как судимость зачастую является весомым аргументом в пользу отказа лица от совершения преступления.

Введение института уголовного проступка по нашему мнению нецелесообразно, ввиду того, что внесение изменений в уже действующие нормы уголовного закона, исключит возможность назначения уголовного наказания в виде лишения свободы по конкретным видам преступлений небольшой и средней тяжести, совершенным впервые.

Важно также обеспечить условия для того, чтобы лица, совершившие уголовный проступок, в том числе и несовершеннолетние, были внесены в те же централизованные учеты, что и обычные преступники. Также, следует ожидать, что подавляющее большинство различных нормативно-правовых актов, связанных с ограничением для лиц, имеющих 
судимость, скорее всего, изменятся после принятия рассматриваемого законопроекта и в них будет включено ограничение для лиц, совершивших уголовный проступок.

В случае исключения сведений о совершении несовершеннолетним преступления, отнесенного к категории уголовного проступка, из централизованных учетов МВД России, органы предварительного расследования могут столкнуться с проблемой искажения сведений о личности, привлекаемого у уголовной ответственности лица.

Следует отметить, что указанный законопроект ранее уже был подготовлен ВС РФ в октябре 2017 года и внесен на рассмотрение в Государственную Думу лишь в декабре 2018 года, однако в т.ч. в связи с нарушением интересов потерпевших, которым совершенным уголовным проступком будет причинен вред, не получил поддержку со стороны Правительства.

Находящийся сегодня на рассмотрении законопроект, предусматривает право потерпевшего на заявление гражданского иска о возмещении вреда, а так же прекращение уголовного дела лишь при условии полного возмещения вреда, позволяющего примирение с потерпевшим. Вместе с тем это не все необходимые изменения, позволяющие ввести данный институт в правоприменительную практику.

В частности, применение института уголовного проступка к несовершеннолетним, совершившим впервые преступления небольшой или средней тяжести, требует уточнения порядка производства дознания по данной категории уголовных дел и определения перечня обстоятельств, подлежащих установлению по уголовному делу. Производство дознания в прежнем объеме не повлияет на сокращение сроков расследования и не отразится на эффективности работы.

В связи с изложенным, считаем, что следует согласиться с мнением Ю.И. Базаровой, что «Зачем тратить время и средства на расследование уголовного дела, если еще в ходе предварительной проверки, очевидно, что имел место уголовный проступок?» [7].

Данная позиция не может быть поддержана в части того, что отказ в возбуждении уголовного дела в данном случае не позволит применить к лицу, совершившему уголовный проступок иные меры уголовно-правового характера, которые, по мнению законодателя, будут введены в УК РФ и будут назначаться только судом.

Таким образом, изучив содержание рассматриваемого законопроекта, мы не можем согласиться с позицией ВС РФ заключающейся в том, что введение института уголовного проступка упростит процедуру расследования и (или) рассмотрения дела судом, что снизит нагрузку на органы предварительного расследования и суды.

Законодателю следует более детально разъяснить, как именно будет производиться дознание и судебное рассмотрение дела, уточнить предмет доказывания по данному виду уголовных дел.

На основании вышеизложенного следует сделать вывод о том, что рассматривая вопрос введения института уголовного проступка необходимо обратить внимание на порядок производства расследования в форме дознания таких категорий уголовных дел, что требует устранения пробелов в уголовно-процессуальном законодательстве, касающемся внесения изменений и дополнений в нормы законодательства, относительно несовершеннолетних подозреваемых и обвиняемых.

Прежде всего, необходимо внести изменения и дополнения в ст. 427 УПК РФ «Прекращение уголовного преследования с применением принудительной меры воспитательного воздействия», изложив ее в следующей редакции.

1. Если в ходе предварительного расследования уголовного дела будет установлено, что имеется предусмотренное частью первой статьи 90 Уголовного кодекса Российской Федерации основание для прекращения уголовного дела или уголовного преследования в отношении несовершеннолетнего подозреваемого, обвиняемого, то следователь с согласия руководителя следственного органа, а также дознаватель с согласия прокурора выносит постановление о прекращении уголовного дела 
или уголовного преследования и возбуждении перед судом ходатайства о применении к несовершеннолетнему обвиняемому принудительной меры воспитательного воздействия, предусмотренной частью третьей статьи 90 Уголовного кодекса Российской Федерации, которое вместе с уголовным делом направляется руководителем следственного органа или прокурором в суд.

2. Если в ходе предварительного расследования уголовного дела о преступлении небольшой или средней тяжести будет установлено, что исправление несовершеннолетнего обвиняемого может быть достигнуто без применения наказания, то следователь с согласия руководителя следственного органа, а также дознаватель с согласия прокурора вправе вынести постановление о прекращении уголовного преследования и возбуждении перед судом ходатайства о применении к несовершеннолетнему обвиняемому принудительной меры воспитательного воздействия, предусмотренной частью третьей статьи 90 Уголовного кодекса Российской Федерации, которое вместе с уголовным делом направляется руководителем следственного органа или прокурором в суд.

3. Суд рассматривает ходатайство и материалы уголовного дела в порядке, установленном частями четвертой, шестой, восьмой, девятой и одиннадцатой статьи 108 настоящего Кодекса, за исключением правил, устанавливающих процессуальные сроки.

4. Суд, получив уголовное дело с обвинительным заключением или обвинительным актом, прекращает его по основаниям, указанным в части первой настоящей статьи, и применяет к несовершеннолетнему обвиняемому принудительную меру воспитательного воздействия.

5. Суд, получив уголовное дело с обвинительным заключением или обвинительным актом, вправе прекратить его по основаниям, указанным в части второй настоящей статьи, и применить к несовершеннолетнему обвиняемому принудительную меру воспитательного воздействия.

6. Суд в постановлении о применении к несовершеннолетнему обвиняемому принудительной меры воспитательного воздействия вправе возложить на специализированное учреждение для несовершеннолетних контроль за исполнением требований, предусмотренных принудительной мерой воспитательного воздействия.

7. В случае систематического неисполнения несовершеннолетним требований, предусмотренных принудительной мерой воспитательного воздействия, суд по ходатайству специализированного учреждения для несовершеннолетних отменяет постановление о прекращении уголовного преследования и применении принудительной меры воспитательного воздействия и направляет материалы уголовного дела руководителю следственного органа или начальнику органа дознания. Дальнейшее производство по уголовному делу продолжается в порядке, установленном частью второй настоящего Кодекса.

8. Прекращение уголовного преследования по основаниям, указанным в части первой или части второй настоящей статьи, не допускается, если несовершеннолетний подозреваемый, обвиняемый или его законный представитель против этого возражают.

$$
* * *
$$

1. Состояние преступности в Российской Федерации за январь-декабрь 2020 года // Официальный сайт МВД России (дата обращения 14.03.2021). 
2. Отчет начальника ГУ МВД России по г. Москве О. А. Баранова за 2019 год в Московской государственной думе // сайт ГУ МВД России по г. Москве (дата обращения: 18.03.2021).

3. Проект федерального закона (Законопроект № 1112019-7) «О внесении изменений в Уголовный кодекс Российской Федерации и Уголовно-процессуальный кодекс Российской Федерации в связи с введением понятия уголовного проступка» // СОЗД ГАС «Законотворчество» 2021 ГД РФ // URL: http:// www.sozd.duma.gov.ru. (дата обращения: 19.03.2021).

4. Официальный отзыв Правительства РФ. Проект федерального закона (Законопроект № 1112019-7) «О внесении изменений в Уголовный кодекс Российской Федерации и Уголовно-процессуальный кодекс Российской Федерации в связи с введением понятия уголовного проступка» // СОЗД ГАС «Законотворчество» 2021 ГД РФ // сайт, URL: http:// www.sozd.duma.gov.ru. (дата обращения: 19.03.2021).

5. Пояснительная записка к проекту федерального закона «О внесении изменений в Уголовный кодекс Российской Федерации и Уголовно-процессуальный кодекс Российской Федерации в связи с введением понятия уголовного проступка»// СОЗД ГАС «Законотворчество» 2021 ГД РФ // сайт, URL: http:// www.sozd.duma.gov.ru. (дата обращения: 19.03.2021).

6. Российская газета - Федеральный выпуск № 7412 (246). [Электронный ресурс]. URL:https://rg.ru/2017/10/30/v-ugolovnom-kodekse-rossii-poiavitsia-institut-ugolovnogo prostupoka.html (Дата обращения: 17.03.2021).

7. Базарова Ю.И. «Уголовный проступок». Актуальные проблемы науки и практики [Электронный ресурс] :сб. науч.тр. / Дальневост. юрид. ин-т МВД России. - Электрон. науч. изд. - Хабаровск: РИО ДВЮИ МВД России, 2018. - Вып. 2 - 2018. С. 35. Режим доступа к вып.: https: // media.mvd.ru (дата обращения: 18.03.2021).

Палеха P.P., Бокова А.О.

Психологическая теория права Л.И. Петражицкого: эволюция идей и их основное содержание

Центральный филиал ФГБОУ ВО «Российский государственный университет правосудия» (Россия, Воронеж)

doi: 10.18411/trnio-12-2021-189

\section{Аннотация}

В статье представлена оригинальная психологическая теория права Л.И. Петражицкого, показаны ее основные идеи, их развитие и значение для современного правопонимания.

Ключевые слова: психологическая теория права, Л.И. Петражицкий, правопонимание, эмоции, психика, интуитивное право, позитивное право.

\section{Abstract}

The article presents the original psychological theory of law by L.I. Petrazhitsky, shows its main ideas, their development and significance for modern legal understanding.

Keywords: psychological theory of law, L.I. Petrazhitsky, legal understanding, emotions, psyche, intuitive law, positive law.

Одно из наиболее востребованных современных направлений правопонимания основанное на психологических механизмах раскрытия сущности права и правовых явлений, обязано своим оформлением как прогрессивному направлению правовой мысли психологической теории права Л.И. Петражицкого. Данное учение является весьма неординарным, как и сама личность выдающегося учёного с мировым именем - Льва Иосифовича Петражицкого (1867-1931). Нестандартность подхода Л.И. Петражицкого к пониманию права находится в плоскости его личностной социализации и социальноисторической детерминированности.

Факторы первого порядка (личностная социализация) связаны с обучением Л.И. Петражицкого на медицинском факультете Киевского Императорского университета Св. Владимира, где и было положено начало научной деятельности направленной на исследование влияния психики на развитие этических и правовых норм. Во второй половине 1885-1886 гг. Л.И. Петражицкий переводится на юридический факультет этого же 